\title{
Research on Wood Chips of Cation Modification and Its Adsorption of Activated Red
}

\section{Longlei Wang}

College of Materials Engineering, Fujian Agriculture and Forestry University, Fuzhou, China

Keywords: Adsorption, Cationic, Graft, Dye wastewater

\begin{abstract}
In this thesis, cationic monomer-grafted wood was prepared by using hard-wood chips with channels that can be used for wastewater treatment. The cationic modified hardwood has the ability to adsorb anionic dye wastewater. The cationic modified wood was used for the adsorption of dye wastes. The paper explores the filtration performances of modified wood chips, including the influence on decoloration rate of Reactive red X-3B of modified WOOD- CHPTAC with monomer concentration, the influence on decoloration rate of Reactive red $\mathrm{X}-3 \mathrm{~B}$ of different filtration pressure (flow velocity), the influence on decoloration rate of $\mathrm{PH}$ value of Reactive red $\mathrm{X}-3 \mathrm{~B}$ solution and the nature of reusable experiment of modified wood chips. The results showed that the adsorption rate and decoloration ratio of cationic modified wood was higher than that of untreated wood chips. The cationic modified wood has broad prospects for wastewater treatment.
\end{abstract}

\section{Introduction}

In the twenty-first century, the world we live in is facing a very serious problem of environmental pollution. With the acceleration of industrialization and the surge of population, water pollution is a difficult problem to be solved urgently. The problem of water environmental pollution is very difficult to avoid, especially with the rapid development of industry, the shortage of water and production of sewage treatment, which have made many enterprises in the world to have a strong attention. The scale of production in all walks of life has expanded rapidly, and the amount of water and waste water has increased dramatically, which is of great practical significance to the treatment of wastewater. Nowadays, more than 60, 000 kinds of chemicals are used by human beings. They contain $70 \%$ chemical products which are not good for our health. These terrible substances can cause a series of serious miscellaneous diseases, including various cancers, male and female infertility, the main nervous system of human beings, and the immune system disorder that resists the virus. Therefore, we must pay attention to the sources and characteristics of various pollutants in the water, and what measures we will take to solve this problem. For printing and dyeing wastewater, the sewage composition is complex and the chromaticity is deep, which contains a large amount of organic matter which is difficult to degrade, and the most serious is the large amount of toxic carcinogen in the printing and dyeing wastewater. Therefore, the treatment of waste is a very difficult and valuable. We try new materials and new technologies to improve it.

In this paper, we use hardwood wood chips as the base material and 3- chloro -2- hydroxypropyl three methyl ammonium chloride as cationic monomer. By grafting modification method, the cationic graft modified wood chips which can be used to treat waste water are prepared. The main research contents are as follows: (1) we successfully prepared the wood chips of cation modification; (2) we explored the characterizations of the wood chips of cation modification; (3) we researched the adsorption of Activated Red by wood chips after cation modification.

\section{Experiment and characterization}

\subsection{Experimental materials}

The material used in this experiment is broad leaf wood, the wood is processed into thin wood slices, and then the impurities in the catheter are dissolved in alkaline solution, and the ultrasonic 
wave is accelerated to dissolve. The modified monomer is 3- chlorine -2- hydroxypropyl three methyl ammonium chloride solution, the solvent medium is sodium hydroxide, and the adsorbed sample is active red $\mathrm{X}-3 \mathrm{~B}$ solution. The specific information is shown in the following table:

Table 1. Reagent, formula, purity and source

\begin{tabular}{ccc}
\hline $\begin{array}{c}\text { Molecular formula } \\
\text { or abbreviation }\end{array}$ & Purit & Manufacturer \\
\hline $\mathrm{CH}_{3} \mathrm{CH}_{2} \mathrm{OH}$ & $\geq 99.7 \%$ & Shanghai Titan Scientific Co., Ltd \\
- & - & - \\
$\mathrm{H}_{2} \mathrm{O}$ & - & Prepared by laboratory \\
$\mathrm{NAOH}$ & $\geq 99.5 \%$ & Shanghai Aladdin Bio-Chem Technology Co., \\
$\mathrm{CHPTAC}$ & $\geq 99.5 \%$ & Shanghai Aladdin Bio-Chem Technology Co., \\
$\mathrm{HCl}$ & $98 \%$ & Shanghai Aladdin Bio-Chem Technology Co., \\
\hline
\end{tabular}

\subsection{Apparatus and equipment}

Table 2. Experimental apparatus and equipment

\begin{tabular}{|c|c|c|}
\hline Equipment & Device models & Manufacturer \\
\hline Electronic balance & $\mathrm{CP} 214$ & $\begin{array}{c}\text { Ohaus International Trading (Shanghai) } \\
\text { Co., Ltd }\end{array}$ \\
\hline $\begin{array}{l}\text { Numerical control power } \\
\text { ultrasonic cleaning }\end{array}$ & SCQ-22010 & $\begin{array}{c}\text { Shanghai Shengyan UItrasonic } \\
\text { Instrument Co.,Ltd }\end{array}$ \\
\hline Vacuum drying box & D2F-6020 & $\begin{array}{l}\text { Shanghai Jinghong Experimental } \\
\text { Equipment Co.,Ltd. }\end{array}$ \\
\hline Rotary vane vacuum pump & $2 X Z-4$ & $\begin{array}{l}\text { Zhejiang Taizhou Qiujing Vacuum } \\
\text { Pumps Co.,Ltd. }\end{array}$ \\
\hline $\begin{array}{l}\text { Laboratory special ultra- } \\
\text { pure water machine }\end{array}$ & WP-UP-LH-30 & $\begin{array}{l}\text { Sichuan Water Purifier Equipment Co., } \\
\text { Ltd. }\end{array}$ \\
\hline $\begin{array}{l}\text { Heat collector magnetic } \\
\text { stirrer with constant }\end{array}$ & DF-101S & $\begin{array}{l}\text { Zhengzhou Greatwall Scientific } \\
\text { Industrial and Trade Co., Ltd }\end{array}$ \\
\hline $\begin{array}{l}\text { Adjustable single channel } \\
\text { pipette gun }\end{array}$ & $\begin{array}{l}100-1000 \mathrm{uL} \\
20-200 \mathrm{uL}\end{array}$ & $\begin{array}{l}\text { Shimadzu-GL Sciences (Shanghai) } \\
\text { Laboratory Supplies Co., Ltd. }\end{array}$ \\
\hline Hair drier & RCE-2000 & Taizhou Renjie Electric Co., Ltd. \\
\hline
\end{tabular}

In addition, there are other commonly used beaker $(50 \mathrm{~mL}, 100 \mathrm{~mL})$, antiseptic gloves, test tube frame, drip tube, glass mixer, manual saw, sand paper, $\mathrm{pH}$ test paper, filter device, tweezers, spoons, filter paper and so on.

\subsection{Experimental method}

The hardwood blocks were sawn into thin sheets of the same size and thickness of about $0.5 \mathrm{~cm}$, then grinded with coarse sand paper, and then finely processed with fine sandpaper. The sodium hydroxide solid 0.1 g, 0.5 g, 1 g, 2 g, 4 g, 8 g were obtained by electronic balance, and the ultrapure water of $100 \mathrm{~mL}$ was taken from the beaker of $100 \mathrm{~mL}$, and the sodium hydroxide solid was dissolved in the ultra-pure water, and the concentration of sodium hydroxide solution was 0.001 $\mathrm{g} / \mathrm{mL}, 0.005 \mathrm{~g} / \mathrm{mL}, 0.01 \mathrm{~g} / \mathrm{mL}, 0.02 \mathrm{~g} / \mathrm{mL}, 0.04$, and 0.08 . Use the electronic balance to weigh the good wood slices and record the wood slices with the same quality as the experimental sample. Then the treated wood chips are put into 2 pieces each, and many times are stirred, and the beaker's cup mouth is tightly wrapped with a fresh-keeping film or the seal film, and the treated experimental samples are put into the ultrasonic device. For 10 minutes, dissolve the impurities in the hardwood vessel. Then remove the beaker and remove the wood chips with tweezers and put it on the filter paper. Pour the sodium hydroxide solution into the waste liquid barrel and prevent it from being poured directly into the water pipe of the sink. Then repeat the above steps, the 
preparation concentration is $0.001 \mathrm{~g} / \mathrm{mL}, 0.005 \mathrm{~g} / \mathrm{mL}, 0.01 \mathrm{~g} / \mathrm{mL}, 0.02 \mathrm{~g} / \mathrm{ml}, 0.04 \mathrm{~g} / \mathrm{mL}, 0.08 \mathrm{~g} / \mathrm{mL}$ sodium hydroxide solution, and then add the solution of different amount $(0.5 \mathrm{~mL}, 1 \mathrm{~mL}, 1.5 \mathrm{~mL}, 2$ $\mathrm{mL}, 3 \mathrm{~mL}$ and $4 \mathrm{~mL}$ ), and then in each group of solutions. The two beaker is sealed quickly with a sealing film, and the sample is spread on the heat collector with the experiment processed. At the same time, the agitator is also stirred for 4 hours, and the cationic modified wood with different grafting rates is prepared.

After the complete reaction was completed, the wood slices were removed from the solution, and the reacted wood chips were added to the beaker with ultra-pure water, and the filtered water was replaced every 10 minutes. The mixture of sodium hydroxide and three methyl ammonium chloride was poured into the waste liquid bucket. The wood slices were soaked for two hours. The $\mathrm{pH}$ value was measured by $\mathrm{pH}$ test paper and the test paper was quickly tested and tested. Standard $\mathrm{pH}$ card contrast and use $0.1 \mathrm{~mol} / \mathrm{mL} \mathrm{HCl}$ solution to adjust the $\mathrm{pH}$ value until the solution is neutral, then the block is placed in the reaction liquid for 10 minutes to measure a $\mathrm{pH}$ value, observe whether the $\mathrm{pH}$ value is still neutral, if the solution is neutral, the reaction is completed, and the 2 pieces of wood are blown dry with a blower, annotated, and record preparation for the next. Experimental reserve. Then we use the self-made filter to clamp the wood in the middle and seal it with the sealing film to ensure no leakage. At the same time, the diaphragm vacuum pump is connected to the vacuum pump. First, the $10 \mathrm{~mL}$ ultra-pure water suction cleaning device is added. The filtered water is measured to determine the alkalinity of the interior of the block, and the filtered water is extracted and pumped in the air. The experimental reaction process is shown in Figure 1.

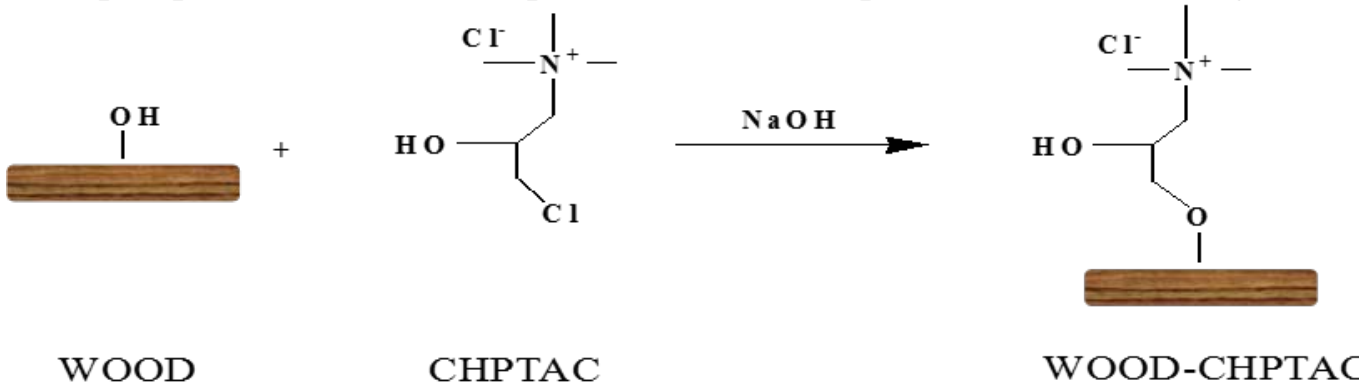

Figure 1. Synthetic Steps of WOOD-CHPTAC

After the experiment was completely reacted, the suction device was closed and the filter was removed, the container was cleaned and the tube mouth was wiped and the cation graft modified wood was taken out to observe the changes of the surface of the wood slices and the penetration of the tube hole. Two to three times the surface of the soaked wood block was soaked with anhydrous ethanol. Water ethanol soaks the wood slices, rinse the vibration with ultrasonic depth for about 10 minutes, and then uses water for ultrasonic washing for 10 minutes, and then puts it into a dry and clean beaker for about 1 hours in a vacuum. After the drying of wood chips is finished, the samples should be weighed and recorded again. A series of processed wood slices were analysed by ATRFTIR, at the same time, the absorbability test was carried out, and the data measured by the experiments were collected, and a visual statistical map was made and analysed.

\subsection{Characterization method}

The total reflectance spectrum was plotted by transform attenuation, and the characteristic peaks of different functional groups before and after modification were analysed. The Fourier infrared spectrometer is equipped with MK II ATR system, and its surface composition is analysed. The measurement wavelength range is $800-4000 \mathrm{~cm}$, the resolution is $2 \mathrm{~cm}$, and the number of scanning times is 64 times.

The unmodified wood slices and different monomer concentration modified wood slices were taken respectively. Each piece of wood was tested and selected $20 \mathrm{~mL}$ glass bottles with $20 \mathrm{mg} / \mathrm{L}$ active red $\mathrm{x}$--3B solution $20 \mathrm{ml}$. The solution absorbency of active red $\mathrm{x}-\mathrm{-} 3 \mathrm{~B}$ was measured after a certain pressure and the concentration was calculated, and the concentration was calculated to 
calculate the concentration of different monomers. The decolorization rate of the modified wood slices to the active red $\mathrm{x}-3 \mathrm{~B}$ solution.

During the filtration process, different operating pressures will affect the adsorption performance of WOOD-CHPTACR on dye molecules. With the increase of pressure, the permeation flux of the dye solution increases. Under the conditions of different permeation flux, the contact situation of dye molecules with WOOD-CHPTACR is different, and then affects the initial decolorization rate of the active red $\mathrm{x}--3 \mathrm{~B}$ solution. The $20 \mathrm{mg} / \mathrm{L}$ active red $\mathrm{x}--3 \mathrm{~B}$ solution $20 \mathrm{~mL}$ is injected into the glass bottle with $20 \mathrm{~mL}$, and the filter is filtered under different pressures. Then, the solution absorbency of active red $\mathrm{x}-3 \mathrm{~B}$ was detected and its concentration was calculated. The decolorization rate of the modified wood slices to the active red $\mathrm{x}-3 \mathrm{~B}$ solution was calculated.

The wastewater with different $\mathrm{pH}$ values will cause the protonation of dye molecules, resulting in the adsorption and filtration performance of materials. The $\mathrm{pH}$ of active red X-ray -3B solution was adjusted to 3.4, 4.4, 5.2, 7.1, 8.9, 9.7 and 10.8 by using $\mathrm{HCl}$ and $\mathrm{NaOH}$. The concentration of $20 \mathrm{~mL}$ was taken as $20 \mathrm{mg} / \mathrm{L}$ active red $\mathrm{x}-$-3B solution by the liquid grafted gun, and the graft ratio of $8.9 \%$ WOOD-CHPTAC was selected as the filter wood. The filtrate of different $\mathrm{pH}$ values was collected at normal pressure and the activity red $\mathrm{x}-\mathrm{-} \mathrm{B}$ was detected. The absorbance of the solution was calculated and its concentration was calculated. The formula was used to calculate the decolorization rate of the active red $\mathrm{x}-3 \mathrm{~B}$ solution with different $\mathrm{pH}$ values after filtration by modified wood chip 2-1.

The regenerative performance of the material is an important index in practical application. The filtered WOOD-CHPTAC is placed in the ultrasonic instrument and the ultrasonic 5 min in the 50 $\mathrm{mL}$ sodium hydroxide solution with a concentration of $2 \%$ is used to rinse and adsorb the adsorbed with ultra-pure water and the two sides filter. Then, the drying oven is placed in the oven, and the filtration washing desorption and filtration cycle is carried out at many times. During the process, the decolorization rate of the active red $\mathrm{x}$-3B solution was measured and calculated.

\section{Surface profile of modified woodchips after filtration}

The surface morphology of the modified wood slices and before and after the filtering were analysed with a digital camera. As shown below, the surface colour of the unmodified wood slices was the same as that of the modified wood before filtering. After the filtration, the surface colour of the unmodified wood was almost no change, and the surface colour of the modified wood WOODCHPTAC became red on the surface of the WOOD-CHPTAC. For the typical reactive red X-ray 3B dye, it shows that the unmodified wood chips are not adsorbed on the active red $\mathrm{x}-3 \mathrm{~B}$ during the filtration process, and the modified wood WOOD-CHPTAC can filter and intercept active red $\mathrm{x}-3 \mathrm{~B}$ molecules.
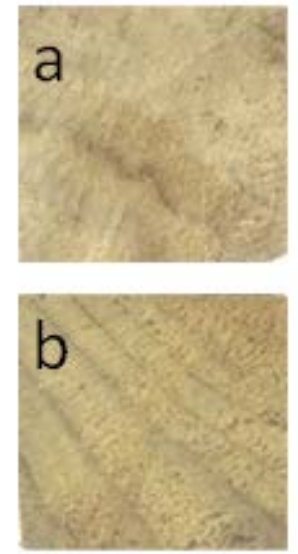

before

filtration
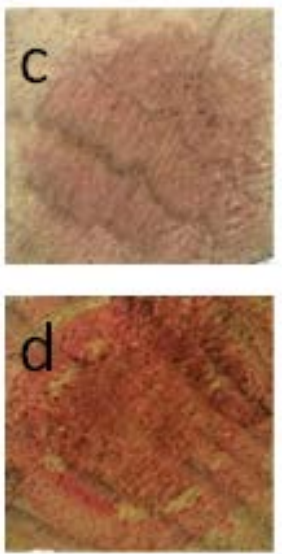

after

filtration

Figure 2. Images of WOOD (a) and WOOD-CHPTAC (b) before and after filtration 


\section{Filtration performance of modified wood chips}

\subsection{Influence on decoloration rate of Reactive red X-3B of modified WOOD- CHPTAC with monomer concentration}

The active red $\mathrm{x}$--3B solution was filtered by unmodified wood chips and wood chips modified with different monomer concentrations. Obviously, under normal pressure, the unmodified wood chips had very weak filtration effect on the active red $\mathrm{x}-3 \mathrm{~B}$, and the decolorization rate was only about 3.2\% after filtration. The cationic monomer CHPTAC grafted on the surface of the wood and the catheter can adsorb anionic substances by electrostatic action, thus filtering the reactive red $\mathrm{X}-$ 3B dye in the water, and with the increase of the grafting rate, the decolorization rate increases by more than $90 \%$.

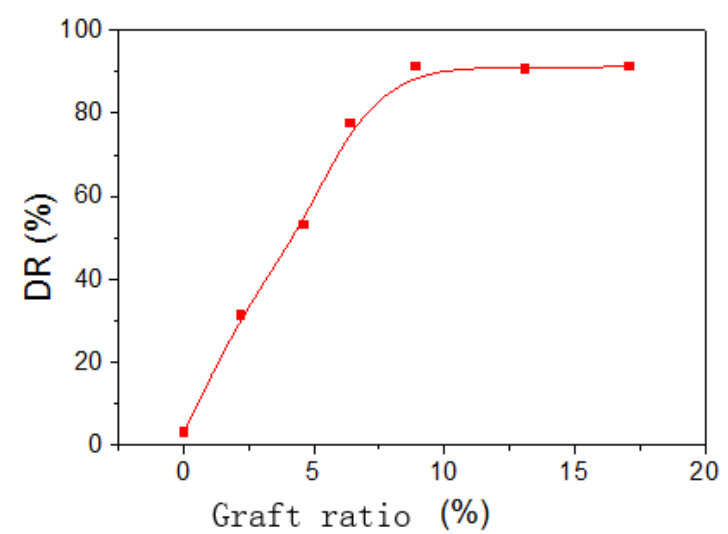

Figure 3. The DR of Reactive red X-3B by WOOD WOOD-CHPTAC with different graft ratio after filtration

\subsection{Influence on decoloration rate of Reactive red $X-3 B$ of different filtration pressure (flow velocity)}

During the filtration process, the permeation flux of the dye solution increases with the increase of pressure, and the permeation flux affects the contact between the dye molecules and the WOODCHPTAC, and then affects the initial decolorization rate of the active red $\mathrm{x}-\mathrm{-} 3 \mathrm{~B}$ solution. According to the above analysis, the decolorization rate of active red $x-3 B$ decreases with the increase of permeate flux, and the decolorization rate decreases sharply with the increase of permeate flux at higher permeation flux. The decolorization rate of active red $\mathrm{x}--3 \mathrm{~B}$ is still above $85 \%$ after WOODCHPTAC filtration at $9.36 \times 10 \mathrm{~L} / \mathrm{m} / \mathrm{h}$, indicating that the cation site in the modified wood chip can still be in good contact with the dye molecules under this operating condition and can be adsorbed in the catheter by electrostatic action. With the increase of permeation flux and the increase of flow rate, the contact between dye molecules and cation sites is limited, so the dye molecules are cut down and the decolorization rate decreases.

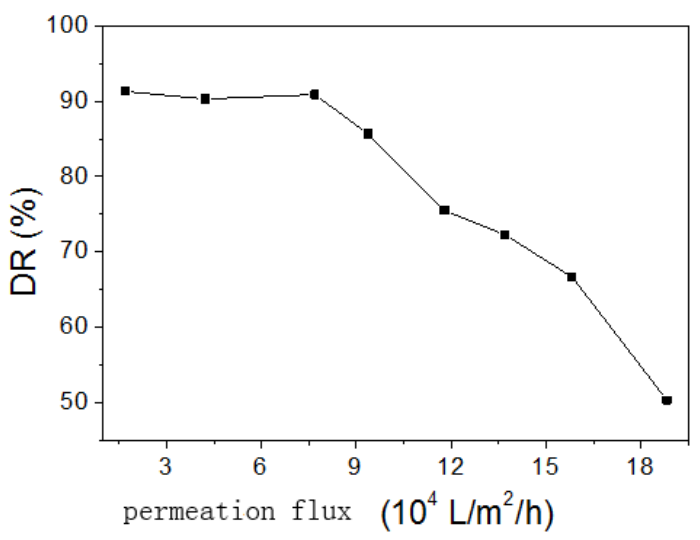

Figure 4. Relationship between decolorization rate and permeation flux 


\subsection{Influence on decoloration rate of $\mathrm{PH}$ value of Reactive red $\mathrm{X}$-3B solution}

In practical production, dye wastewater with different $\mathrm{pH}$ values can lead to changes in the protonation state of dye molecules, affecting the performance of membrane materials for removal of dye molecules. In this paper, the filtration and decolorization of anionic dye active red $\mathrm{x}-3 \mathrm{~B}$ solution with $\mathrm{pH}$ value of $8.9 \%, 3.4,4.4,5.2,7.1,8.9,9.7$ and 10.8 of the modified wood WOODCHPTAC with grafting ratio was studied. The $\mathrm{pH}$ value of the dye solution has a great influence on the filtration decolorization rate. Under the condition of acid and neutral, the decolorization rate of the modified wood chip WOOD-CHPTAC to the active red $\mathrm{x}-3 \mathrm{~B}$ is above $90 \%$, and the decolorization rate decreases with the increase of the $\mathrm{pH}$ value under the alkaline condition. Because the active red $\mathrm{x}-3 \mathrm{~B}$ molecule contains the sulfonic radical group, under the alkaline condition, the anion with the negative charged hydroxide in the solution is competitive, so the electrostatic adsorption of the cationic group in the surface of the WOOD-CHPTAC and the catheter is weakened, and some of the active red $\mathrm{x}-3 \mathrm{~B}$ molecules can not be filtered and intercepted, resulting in a decrease of the decolorization rate.

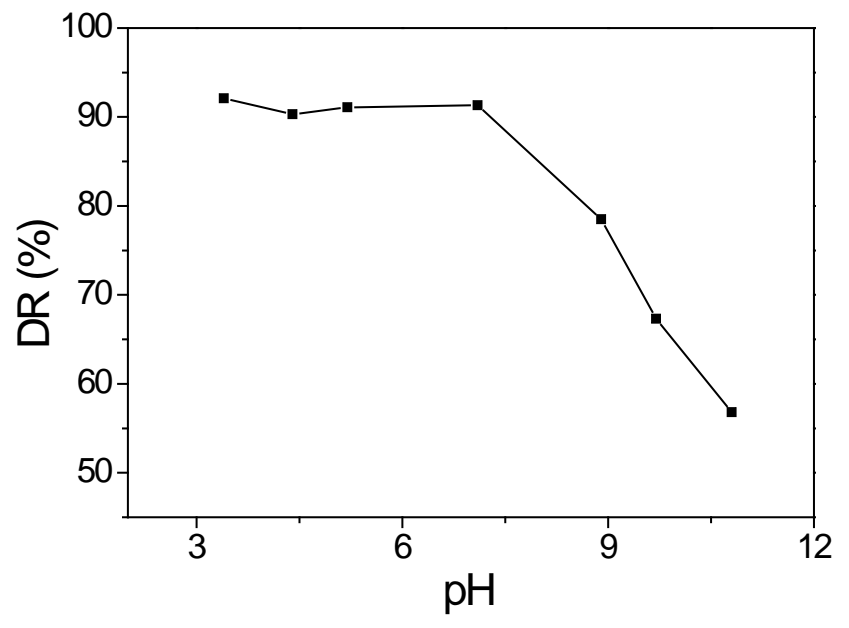

Figure 5. Effect of Solution pH on Adsorption Equilibrium

\subsection{Nature of reusable experiment of modified wood chips}

In the case of 4 regeneration, the decolorization effect of WOOD-CHPTAC on active red remained about $90 \%$. With the increase of recycling times, the decolorization effect of active red solution gradually weakened. After 10 regeneration, the decolorization rate of active red $\mathrm{x}$--3B was still higher than $80 \%$. Therefore, WOOD-CHPTAC has good reusability and stability.

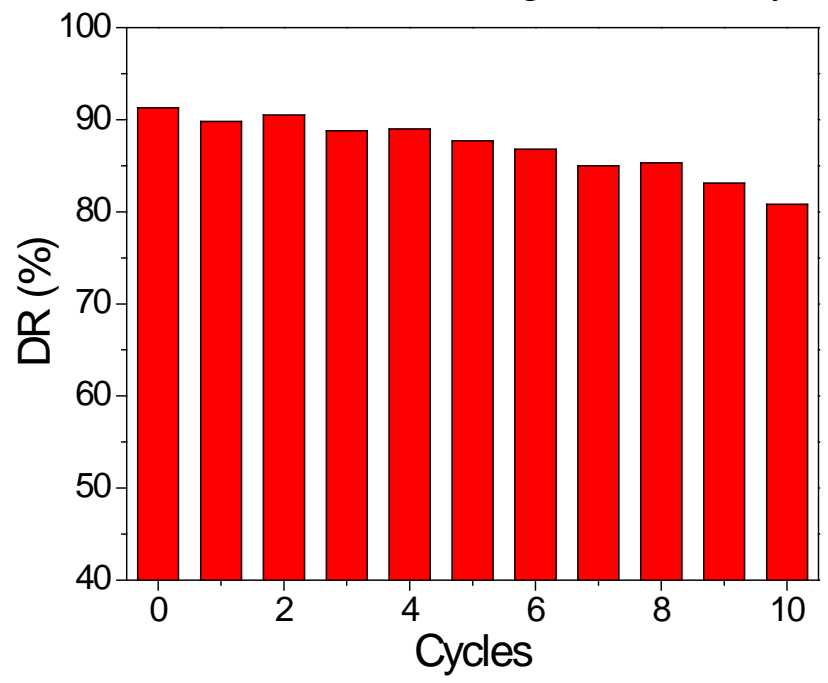

Figure 6. Recycling property of CP-CHPTAC 


\section{References}

[1] Zhang S, Zhang Y, Bi G, et al. Mussel-inspired polydopamine biopolymer decorated with magnetic nanoparticles for multiple pollutants removal[J]. Journal of Hazardous Materials, 2014, 270: 27-34.

[2] Mathieu-Denoncourt J, Martyniuk C J, de Solla S R, et al. Sediment Contaminated with the Azo Dye Disperse Yellow 7 Alters Cellular Stress- and Androgen-Related Transcription in Silurana tropicalis Larvae[J]. Environmental Science \& Technology,2014, 48(5): 2952-2961.

[3] Crini G. Non-conventional low-cost adsorbents for dye removal: A review[J]. Bioresource Technology, 2006, 97(9): 1061-1085.

[4] Hua Yuan, Hai Chi, Weizhong Yuan. Ethyl cellulose amphiphilic graft copolymers with LCSTUCST transition: Opposite self-assembly behavior, hydrophilic-hydrophobic surface and tunable crystalline morphologies[J]. Carbohydrate Polymers, 2016, 147: 261-271.

[5] de Luna L A V, da Silva T H G, Pupo Nogueira R F, et al. Aquatic toxicity of dyes before and after photo-Fenton treatment[J]. Journal of Hazardous Materials, 2014, 276: 332-338.

[6] Gupta V K, Suhas. Application of low-cost adsorbents for dye removal - A review[J]. Journal of Environmental Management, 2009, 90(8): 2313-2342.

[7] Lin X, Ma W, Wu $\mathrm{H}$, et al. Superhydrophobic magnetic poly (DOPAm-coPFOEA)/Fe3O4/cellulose microspheres for stable liquid marbles[J]. Chemical Communications, 2016, 52(9): 1895-1898.

[8] Wu H, Wu L, Lu S, et al. Robust superhydrophobic and superoleophilic filter paper via atom transfer radical polymerization for oil/water separation[J]. Carbohydrate Polymers, 2018, 181: 419425.

[9] Tang Z, Li W, Lin X, et al. TEMPO-Oxidized Cellulose with High Degree of Oxidation[J]. Polymers, 2017, 9(9): 421.

[10] Zhou X, Lin X, White K L, et al. Effect of the degree of substitution on the hydrophobicity of acetylated cellulose for production of liquid marbles[J]. Cellulose, 2016, 23(1): 811-821.

[11] Habibi Y. Key advances in the chemical modification of nanocelluloses [J]. Chemical Society Reviews, 2014, 43(5): 1519-1542.

[12] Annadurai G, Juang R S, Lee D J. Use of cellulose-based wastes for adsorption of dyes from aqueous solutions[J]. Journal of Hazardous Materials, 2002, 92(3): 263-274.

[13] Hansson S, Carlmark A, Malmström E, et al. Toward industrial grafting of cellulosic substrates via ARGET ATRP[J]. Journal of Applied Polymer Science, 2015, 132(6): 811-819.

[14] Saber-Samandari S, Saber-Samandari S, Heydaripour S, et al. Novel carboxymethyl cellulose based nanocomposite membrane: Synthesis, characterization and application inwater treatment[J]. Journal of Environmental Management, 2016, 166: 457-465.

[15] Chen F, Gong A S, Zhu M, et al. Mesoporous, Three-Dimensional Wood Membrane Decorated with Nanoparticles for Highly Efficient Water Treatment[J]. ACS Nano, 2017, 11(4):4275.

[16] Song Y B, Zhang J, Gan W P, et al. Flocculation Properties and Antimicrobial Activities of Quaternized Celluloses Synthesized in NaOH/Urea Aqueous Solution[J]. Industrial \& Engineering Chemistry Research, 2010, 49(3): 1242-1246. 